\title{
Construyendo discursos frente a la movilización: Estado y grandes empresas en la conflictividad ambiental en España (1940-1980)
}

Constructing discourses against mobilization: the State and big companies in environmental conflicts in Spain (1940-1980)

DOI: 10.5935/2237-2717.20160007

\author{
Ana Cabana Iglesia \\ Universidade de Santiago de Compostela \\ ana.cabana@usc.es \\ España \\ Daniel Lanero Táboas \\ Universidade de Santiago de Compostela \\ daniel.lanero@usc.es
}

Recibido: 15 de marzo de 2016

Aprobado: 30 de mayo de 2016

\section{RESUMEN}

Este artículo analiza los discursos de dos actores principales de la conflictividad ambiental durante el franquismo y la transición a la democracia en España: la administración del estado y las grandes corporaciones industriales, a los que hasta ahora se ha prestado muy poca atención. En el caso de la administración pública, se estudia el discurso de los organismos estatales encargados de llevar a cabo la política franquista de repoblación forestal, prestando una especial atención a los ingenieros de montes y a su discurso como cuerpo profesional. Por su parte, las grandes empresas españolas impulsaron, con el apoyo de la dictadura, grandes proyectos industriales (en sectores como la industria química, la energía o las comunicaciones) que provocaron intensos conflictos ambientales. Las empresas trataron de contrarrestar este malestar social con potentes campañas publicitarias y de opinión en los medios de comunicación, en las que "modernización", "desarrollo" y "empleo" actuaron como ideas - fuerza sobre las que cimentar su discurso para ganar partidarios en el campo de batalla de la opinión pública.

\section{Palabras Claves}

Discurso, Ambiental, Conflicto.

\section{ABSTRACT}

This article analyses the discourses of two main actors in environmental conflict under Francoism and Transition to democracy in Spain: the Central Administration and the big industrial corporations, who have received, before today, limited attention. In the case of Central Administration, we study the discourse of Central boards carrying out the francoist policy of reforestation, paying special attention to the forestry engineer's discourse as a professional board. For their part, the biggest Spanish companies promoted, with the support of the dictatorship, large industrial projects (in chemical, energy or communication transport sectors) that provoked strong environmental conflicts. The companies tried to counteract this social unrest with powerful advertising and opinion campaigns in the media, constructing their discourse with concepts like "modernisation", "development" or "employment" to win the fight in the battlefield of a new public opinion.

\section{KEYWORDS}

Discourse, Environmental, Conflict. 


\section{Introducción}

El estudio de los conflictos ambientales se ha convertido en una de las vías predilectas para el análisis de las relaciones entre sociedad y medioambiente en los últimos tiempos. Es innegable también el hecho de que esos análisis han contribuido a renovar sustancialmente los contenidos de la historia social y la historia agraria con sugerentes conceptualizaciones teóricas y herramientas metodológicas. Pero también, y así lo entendemos en este trabajo, creemos que los conflictos ambientales pueden ser leídos en una clave que no ha concitado por el momento gran interés: el análisis de los discursos que las partes implicadas en el desacuerdo ponen en liza. En ellos entendemos que se podrían intentar escudriñar los valores y creencias de protagonistas y antagonistas.

Cuando se crea el discurso, estamos otorgando validez al hecho social, es decir, el discurso es una forma de conformación de la realidad o, en todo caso, una manera de evidenciar el posicionamiento social frente a dicha realidad. El discurso puede producir realidad o, en todo caso, interpretarla. En ambas opciones es la herramienta a través de la cual los seres humanos operan a nivel ontológico. Pensamiento y lenguaje van inexorablemente unidos de modo que no ha lugar que uno se produzca sin el otro. La verbalización es una forma de acción social y analizar la estructura del discurso ayuda a desentrañar no sólo las categorías sino la estructura y formas de clasificación y jerarquización. Analizar el discurso nos ayuda a traducir los significados con los que operan los sujetos. ${ }^{1}$ Decodificar el mensaje pasa necesariamente por observar, entender, analizar y desenmarañar los discursos y esa es nuestra pretensión en estas páginas.

Y proponemos llevar a cabo dicha observación empleando tres estudios de caso, tres conflictos que tuvieron a Galicia como espacio privilegiado. Los tres tienen en común, además de su impacto en tierras gallegas, que se desarrollan durante un mismo periodo histórico, la dictadura del general Franco (1939-1975), su naturaleza ambiental, pues son los recursos naturales los que nuclean la disputa y que se derivan de la imposición continua y progresiva de la lógica industrial sobre el territorio rural. ${ }^{2}$ Para lograr esta finalidad, el espacio rural fue conceptualizado como ente abastecedor de materias primas, primero con la autarquía y más adelante con la planificación indicativa de la economía. Si durante el periodo autárquico la dirección de los programas industrializadores corrió a cargo del Estado, a partir de los años cincuenta será el capital privado el que adquiera el papel protagonista. Este será uno de los elementos que distingan los casos de estudio que presentamos. Hemos escogido un conflicto ambiental que se inscribe en el periodo autárquico y otros dos conflictos que responden a la actuación de intereses industriales en la etapa final de la dictadura franquista, prolongándose su desarrollo al inicio de la transición a la democracia. La decisión de analizar conflictos con esta clara divergencia está en relación con nuestra pretensión de evidenciar si ha existido una evolución en los discursos cuando estos eran formulados para operar frente a la opinión pública, caso de los conflictos acontecidos en los años setenta, o cuando ésta directamente no existía, caso del conflicto que se desarrolla en la década de los cuarenta, porque el terror, la represión y una contienda civil habían acabado con cualquier veleidad que pudiera remitir a la idea de

\footnotetext{
${ }^{1}$ Xesus Rodrígues Campos, Lingua, linguaxe e experiencia. A perspectiva antropolóxica e as implicacións filosóficas (Santiago de Compostela: Universidade de Santiago de Compostela, 2001).

2 En un trabajo anterior sobre la conflictividad existente en Galicia durante la dictadura hemos distinguimos tres grandes categorías, 1) los conflictos ambientales; 2) los derivados de la crisis de industrialización de la agricultura y 3 ) los de tipo "mixto", que combinan características de los dos anteriores. Los primeros serían aquellos que con frecuencia suponen una modificación impuesta del modo de uso de los mismos (de campesino a industrial). Los conflictos derivados de la crisis de industrialización de la agricultura tienen en su origen el cambio de paradigma en el modelo de desarrollo agrario que supuso la imposición de la Revolución Verde a partir de la década de 1960.Un análisis pormenorizado en Ana Cabana Iglesia et al., "Dinámicas políticas de la sociedad rural gallega: entre la agonía de la dictadura y la implantación de la democracia (1970-1978)", Historia del Presente 21 (2013): 123-144.
} 
ciudadanía organizada y a enunciación de afirmaciones que pudieran contradecir en algún punto las disposiciones del Estado.

El conflicto ambiental que hemos considerado como estudio de caso en los años cuarenta del siglo XX ha sido el originado al implementar el Estado dictatorial una política gubernamental específica y estratégica en su programa económico, la repoblación forestal. Esta disposición, como veremos, rompía el sistema de propiedad tradicional así como los modos de uso y gestión con los que hasta entonces se había caracterizado el monte vecinal (monte de propiedad colectiva y uso agrosilvopastoral) en espacios como Galicia. Para analizar los argumentos que sirvieron para articular y legitimar ante la opinión pública el discurso de las grandes empresas españolas en el marco de conflictos ambientales provocados por su propia actividad en los años setenta, hemos elegido dos conflictos. Analizaremos en primer lugar el discurso público de la empresa eléctrica FENOSA (Fuerzas Eléctricas del Noroeste SA) en el conflicto provocado por la explotación de una mina de lignito en la parroquia de Encrobas (Cerceda, A Coruña). Cerraremos nuestro estudio con el enconado debate público que se articuló alrededor de la construcción de la Autopista del Atlántico, una vía terrestre de alta capacidad que pretendía comunicar Galicia de norte a sur siguiendo la línea del litoral atlántico. Se trataba de proyectos industriales a gran escala orientados al desarrollo de sectores económicos (energía, química, comunicaciones...) considerados estratégicos por la administración del Estado, la cual, tanto durante el franquismo como en la transición los apoyó abiertamente, cuando no los impulsó directamente a través de grandes empresas públicas.

Ambos conflictos comparten, como hemos indicado, un mismo contexto histórico, pues, aunque su origen está en los años terminales del franquismo, su fase de apogeo tuvo lugar durante los primeros años de la transición, aproximadamente entre 1976 y 1979. Existen además algunos elementos comunes a ambos casos, que se podrían sintetizar en los siguientes: un contexto bastante más abierto que en las tres décadas anteriores, caracterizado por la incertidumbre en torno al futuro político del país, lo que incorporaba, entre determinados sectores sociales y actores políticos, la expectativa de que el sistema político se pudiese encaminar hacia un modelo de democracia formal; la recuperación (aún con un elevado coste represivo) de las prácticas sociales reivindicativas y la progresiva conformación de una opinión pública "moderna". De hecho, estos dos conflictos, junto con otros cuyo estudio no abordaremos aquí, forman parte del "ciclo de protesta" por el que atravesó la sociedad gallega en su conjunto durante la segunda mitad de la década de $1970 .^{3}$

Este nuevo escenario, en particular, en lo que aquí centra nuestro interés, la articulación de una nueva opinión pública, obligó a que las empresas cuyas actividades estaban provocando niveles elevados de malestar social en algunas comarcas participasen de manera mucho más proactiva en los intensos debates públicos generados alrededor de diferentes conflictos ambientales. ${ }^{4}$ Las dos grandes empresas cuya actuación estudiamos aquí, FENOSA y Autopistas del Atlántico S.A. (AUDASA), construyeron sobre el andamiaje de unos pocos argumentos - tan recurrentes como efectivos - un discurso (en realidad un contradiscurso) que oponer en la areha pública al discurso de aquellos colectivos que se estaban movilizando en su contra. Aunque no sólo, la batalla entre discursos de los movimientos sociales y contradiscursos empresariales se dirimió, sobre todo, en los medios de comunicación de masas, en especial en la prensa escrita.

\footnotetext{
${ }^{3}$ Sidney Tarrow, El poder en movimiento. Los movimientos sociales, la acción colectiva y la política (Madrid: Alianza, 2004).

${ }^{4}$ Carlos H. Filgueira, Hohlen, Dieter (comps), Prensa y transición democrática. Experiencias recientes en Europa y América Latina (Madrid: Iberoamericana, 1994); Juan Mntabes, La prensa del Estado durante la transición política española, (Madrid: CIS, 1989); Lois Álvarez, Prensa ameazada. Desde a transición ó fraguismo, (Santiago: Edicións Lea, 1999).
} 


\section{El discurso forestal de los ingenieros de montes}

La política de repoblación forestal franquista, como veremos, rompía el sistema de propiedad tradicional así como los modos de uso y gestión con los que hasta entonces se había caracterizado en monte vecinal en espacios como Galicia. Galicia es la parte más noroccidental del Estado español y se define históricamente por su condición de espacio rural. En el marco de una agricultura de pequeña explotación como era la gallega, el espacio comunal estaba integrado en el sistema agrario y servía al campesino como lugar de pastoreo para la cabaña ganadera, como espacio de aprovisionamiento de fertilizante natural para las tierras de labor y como prolongación del terreno dedicado al cultivo de cereal de manera temporal. Desarrollaba, además, un papel de primer orden en actividades secundarias en términos económicos, pero de gran utilidad en una agricultura multifuncional: aprovechamiento de leña y madera, suministrador de materiales de construcción y herramientas, caza, frutos silvestres, pesca, etc. ${ }^{5}$ Cabe señalar que no estamos haciendo referencia a un tipo de propiedad residual o minoritaria. Para dar una idea exacta de la trascendencia de este recurso, basta indicar que existirían alrededor de 3.000 unidades comunitarias que ocupan en torno a 700.000 has, lo que representa un $23 \%$ de la superficie total gallega. Dígitos que ascienden hasta el 31,7\% y el 41,8\% para las provincias de Lugo y Ourense respectivamente. ${ }^{6}$

El objetivo de la política forestal franquista era alcanzar unos niveles de producción autóctona de maderas que permitieran el abastecimiento de las industrias estatales de producción de celulosa y pasta de papel y para ello se impulsó y se impuso una política de repoblación masiva. ${ }^{7}$ La repoblación forestal se llevó a cabo en Galicia sobre los comunales, propiedades de los vecinos, definibles desde un punto de vista jurídico como "propiedad privada colectiva". Las peculiares condiciones políticas del primer franquismo (que podríamos datar entre 1939-1960), con la represión y destrucción del entramado asociativo campesino $^{8}$ y el poder omnímodo de las instituciones del régimen, posibilitaron esta auténtica usurpación de la propiedad vecinal. La sociedad rural vio no sólo como se les despojaba de sus propiedades, que pasaron a ser regidas por las autoridades municipales, sino también como se les impedían prácticas económicas imprescindibles para su reproducción. El cambio impuesto por la legislación forestal, el paso de un modo de uso campesino a un modo de uso industrial en uno de esos espacios, desarticuló el equilibrio existente en el agroecosistema. ${ }^{9}$ Desestructuró el hábitat que aseguraba el sustento y ofrecía

\footnotetext{
${ }^{5}$ Xesús Balboa López, O monte en Galicia, (Vigo: Ed. Xerais, 1990).

${ }^{6}$ Grupo dos comúns, Os montes veciñais en man común, (Vigo: Ed. Xerais, 2006).

${ }^{7}$ El sector primario se convirtió en un sector completamente regulado (precios, producción, lugares de venta, etc.) en aras de conseguir la ansiada autarquía, objetivo de la política económica en España a lo largo de la década de 1940. Hubo una decisión firme de las autoridades a cerrar las fronteras a las importaciones y regular la actividad económica nacional con la esperanza de lograr la autosuficiencia. La autarquía y el intervencionismo estatal no eran conceptos enteramente desconocidos, pues ya habían estado presentes en la economía española, pero el aspecto novedoso residía en la intensidad con la que se llevó a cabo: eran irrenunciables y permanentes y, como tal, fueron mantenidos a pesar de su ineficacia. Carlos Barciela (ed.), Autarquía y mercado negro (Barcelona: Crítica, 2003). Sobre la autarquía específicamente forestal, Eduardo Rico Boquete, "Autarquía e indusfria de la celulosa en España en el periodo 1939-1956" en Daniel Lanero Táboas y Freire, Dulce, Agriculturas e innovación tecnológica en la Península Ibérica (1946-1975), (Madrid: Ministerio de Medio Ambiente y Medio Rural y Marino, 2011), 167-190.

${ }^{8}$ Ana Cabana Iglesia, Cabo Villa Verde, Miguel, "Cuando lo viejo muere y lo nuevo no acaba de nacer: la represión del asociacionismo agrario en Galicia (1936-1945)" en Jesús de Juana y Xulio Prada, Lo que han hecho en Galicia (Barcelona: Crítica, 2006), 165-185.

${ }^{9}$ Un equilibrio que no estaba exento de 'conflictividad intramodal' según la disquisición de Guha y Gadgil, es decir, de disputas entre los campesinos entre sí o con otros grupos sociales por la atribución de recursos naturales, pero dentro del modo de uso campesino. Rarmachandra Guha y Gadgil, Madhav, "Los hábitats en la historia de la humanidad", Ayer 11 (1993): 49-11. Sobre este tipo de conflictividad intramodal en Galicia, vd. Luís Guitián Rivera, "La destrucción histórica del bosque en Galicia", Semata 13 (2001): 105-106.
} 
las condiciones ambientales necesarias para garantizar la supervivencia y la reproducción. La ruptura de los vínculos de las comunidades campesinas con el "espacio socioambiental," ${ }^{10}$ con su monte, provocó una importante y denodada conflictividad medioambiental. Las resistencias campesinas surgieron ante la quiebra de la plena libertad de gestión de los montes privados y contra la nueva ordenación del espacio rural que se había establecido a raíz de las disposiciones liberales en términos de iure y que el franquismo se encargó de aplicar y profundizar.

Evidentemente el monte es un ecosistema que refleja los modos de organización y los procesos socioeconómicos de una determinada sociedad, pero hay más. También están presentes los significados culturales e ideológicos que se le atribuyen y que delimitan otra constelación de fenómenos de notable trascendencia: creencias, actitudes y valores relacionados con el monte que, evidentemente, orientaron la acción social hacia el mismo. ${ }^{11}$ Es decir, a una lógica productiva y medioambiental distinta y a un proceder autoritario, se une un desacuerdo cultural o simbólico que explica la profundidad alcanzada por el conflicto entre Administración forestal y comunidades. Podríamos aplicar a la población rural gallega las palabras de Lucea Ayala en referencia al a conflictividad social de las comunidades rurales aragonesas, cuando señala que éstas lucharon por salvaguardar los "espacios vacíos de capitalismo" con las armas de una "economía moral" de valores, derechos y obligaciones, que protegía los mecanismos de acceso a la subsistencia. ${ }^{12} \mathrm{El}$ monte comunal era históricamente un asidero para aquellos miembros de las comunidades que no podían asegurarse con sus propiedades su sustento y esta condición, a su vez, afianzaba el papel de la comunidad como espacio protector de sus miembros. Este y otros valores y símbolos asociados al monte comunal se vieron truncados y surgieron toda una serie de actitudes y creencias novedosas con respecto al forestal que, por negativas, operaron en el arreciar de la protesta campesina, que no cejó en su empeño de recuperar sus comunales hasta los años ochenta del siglo XX.

Dicho conflicto ha sido examinado desde muy diferentes ópticas, revisando la aplicación de la política forestal, incidiendo en el proceso de descomposición de la propiedad comunal, que se venía forjando desde el siglo XIX en todo el territorio español, en la incidencia ambiental del cambio acontecido en el modo de uso o en las armas empleadas por la población en el intento por defender los intereses de las comunidades cuando estos son antagónicos al dispuesto por el poder político (su trascendencia social, las modalidades de resistencias y su ritmo, sin dejar de tener presentes sus modalidades represivas y los resultados del conflicto). ${ }^{13}$ Quizás el aspecto que ha pasado más

\footnotetext{
${ }^{10}$ Mauricio Folchi, "Conflictos sociales de contenido ambiental: la experiencia histórica y el debate chileno", Ecología Política 22 (2001): 91

${ }^{11}$ Xesús A. Lage Picos, Bosques, sociedades y cultura forestal en Galicia (Vigo: Universidade de Vigo, 2003), 25.

12 Victor Lucea Ayala, "La protesta cotidiana campesina en Zaragoza (1890-1900). Elementos para una interpretación", en Santiago Castillo y Fernández, Roberto (coords.), Campesinos, artesanos, trabajadores. Actas del IV Congreso de Historia Social de España, (Lleida: Milenio, 2001), 157.

${ }^{13}$ Eduardo Rico Boquete, Política forestal e repoboacións en Galicia (1941-1971) (Santiago de Compostela: USC, 1995); Xaquín Fernández Leiceaga, Economía (política) do monte galego, (Santiago de Compostela: USC, 1991); David Soto Fernández, y Lourenzo Fernández Prieto, "La conflictividad en los montes vecinales de Galicia. Una respuesta a la política forestal del franquismo", In Fontana, Joseph, Historia i Projecte Social. Reconeixement a una trajetoria (Barcelona: Crítica, 2004), 1726-1742; Araceli Freire Cedeira, Conflictividad social en el medio rural gallego (1939-1975): el caso de los montes vecinales en mano común, Tesis Doctoral USC (inédita); Ana Cabana Iglesia et al., "Resistindo polo común: as comunidades rurais galegas contra as políticas florestais do franquismo" en Diego P. Cerezales, Fátima S. e M. FERREIRA y José Neves, Da Economia Moral da Multidão à Arte de Não Ser Governado - E. P. Thomson e James C. Scott na Ibéria (Lisboa: 100LUZ Editora), 69-90; Ana Cabana Iglesia, "Unha historia de desencontros entre Estado e veciñanza. A conflitividade arredor dos montes en man común", en Pegerto Saavedra Fernández et al., A terra en Galicia. Pasado, presente e futuro, (Lalín: UMP-Concello de Lalín, 2014), 212-231; David Soto Fernández, "De la multifuncionalidad a la especialización, la irrelevancia y la reinvención. Los montes de Galicia durante la transición socio-ecológica (1960-2010)", Comunición al XV Congreso de Historia Agraria dē la SEHA. (Lisboa, 2016). La conflictividad detectada en la Galicia rural alrededor de la repoblación forestal franquista ha comenzado a ser ya historiada para otros territorios del Noroeste de
} 
desapercibido haya sido el del discurso que generó la disputa de parte del personal de la Administración forestal encargado de llevarlo a cabo y ello, por supuesto, tiene sus explicaciones. La principal, y puede que más evidente, es el contexto. La existencia de una férrea dictadura salida de una contienda civil, explica que la imposición de las políticas no tuviera que ver en absoluto con el proselitismo del régimen, al menos en sus primeras dos décadas de existencia. Las políticas se llevaban a cabo por el interés del Estado y la capacidad de infundir miedo en una población que, famélica y depauperada, se sabía incapaz de hacer más que retrasar o erosionar en algún punto tales disposiciones con actuaciones puntuales (incendios, quejas, pleitos, etc.). En esta tesitura los historiadores no hemos prestado una atención preferente a los discursos que rodeaban a las disposiciones legislativas por entender que su presencia no era más que un aderezo insustancial.

En este texto no prestaremos atención al discurso de las más destacadas autoridades o cargos de la Administración forestal española. ${ }^{14}$ Influyentes ingenieros de montes cuyas intervenciones políticas se encuentran en disertaciones públicas o en ciertas publicaciones que servían de portavoz de sus políticas, caso de la revista Montes. Entendemos que esa podría ser una opción válida para acercarnos al conflicto, pero hemos preferido operar con una perspectiva más precisa y también diferente a la que tomaremos para analizar el discurso empresarial. Hemos empleado como fuente no las alocuciones con una finalidad pública y política; las destinadas a convencer o argumentar sus posturas ante la opinión pública en general, sino los documentos de corte más técnico, especialmente los consorcios, escritos solo para la comunidad rural en cuestión a la que iba destinado el trabajo de repoblación y para la propia Administración. Se trata de contratos administrativos en los que, ya fuere de manera voluntaria, ya de modo forzoso, se estipulaba la repoblación total o parcial de un monte concreto. Dichos contratos fueron buscados, negociados y redactados por ingenieros forestales de las distintas administraciones (estatal, provincial y distrito) y en ellos, dichos profesionales dejan ver sus postulados y opiniones con respecto al proceso de repoblación forestal y a la posición contraria a los mismos de la población rural. En Galicia se consorciaron alrededor de 475.000 ha de monte comunal. ${ }^{15}$ Evidentemente no todos los ingenieros eran igualmente aficionados a expresar sus principios y valores en los escritos y, debemos incidir en este punto, en muchas ocasiones los consorcios parecen ser una meras copias unos de otros con mudanzas solo en el nombre del monte a repoblar y en las cantidades expresadas (hectáreas, plantas necesarias para repoblar, etc.), lo que limita considerablemente su riqueza como fuente. Pero aun así nos presenta la oportunidad de acercarnos a la opinión de los ingenieros que realizan su actividad diaria en la esfera más próxima a las comunidades, lo que los incita a defender su acción frente a la negativa de aquellas a aceptarla como positiva.

Los ingenieros de montes que consorciaron los montes comunales gallegos en los años cuarenta y cincuenta del siglo XX hicieron una enconada defensa de la política de repoblación, que convertía los comunales en superficies forestales alejándolos de su tradicional vocación multifuncional intercalando en los documentos técnicos que firmaban párrafos completos 0 , más usualmente, pequeños apuntes, en los que dejaban caer argumentaciones que podemos considerar recurrentes y que creemos poder sintetizar en varios axiomas fundamentales, todos ellos interrelacionados como se verá:

\footnotetext{
España, como las provincias noroccidentales de Castilla y León (León y Zamora) o Asturias. Un ejemplo en Eduardo Rico Boquete, "Política forestal y conflictividad social en el noroeste de España durante el primer franquismo, 1939-1959", Historia Social 38 (2000): 117-140.

${ }^{14}$ Eduardo Rico Boquete, ed., Pensamento forestal nò século XX (Santiago de Compostela: Xunta de Galicia, 1999).

${ }^{15}$ Rico Boquete, 1995.
} 
-a ellos les asistía la razón en el conflicto porque miraban por los intereses de la nación y eran los que poseían "el saber", los conocimientos avalados por la erudición científica. Con esta "munición" la mirada a los antagonistas era, obligatoriamente, desde la atalaya de la superioridad.

- en relación con lo anterior, no cabía asumir en algún punto o negociar el punto de vista de los antagonistas, porque no solo eran pocos, en comparación con la "nación", e "ignorantes", no comprendían que los espacios a monte debían ser regidos por la Dasometría, es decir, tenían que ser áreas arboladas. Es más discernían que, finalmente, las comunidades de vecinos entenderían ("verían") los beneficios de esa vocación forestal.

-y, en correlación con esto último, la dedicación forestal no podía convivir con los usos agrosilvopastoralés porque estos eran ciertamente nefastos a todos los niveles (repercusiones edáficas y botánicas, escasez de rendimientos, etc.).

Veremos más detenidamente algunos de estos aspectos del discurso de los forestales que firmaron consorcios para la repoblación de los montes gallegos. "Vengo a ocuparme de la mitad del territorio español que no produce absolutamente nada". Octavio Elorrieta, uno de los ingenieros de montes más importantes e influyentes del primer tercio del siglo XX en España empezó así su discurso en la Asamblea Nacional durante la Dictadura de Primo de Rivera en $1928 .{ }^{16}$ Según él, las tierras a monte se dedicaban a usos poco adecuados y estaban explotadas por debajo de sus posibilidades. Esta idea va a estar insistentemente presente en la documentación que manejan los ingenieros veinte años después cuando describen cómo se realizarán los trabajos de repoblación. El ingeniero José Luque y Vieira de Andreu, uno de los firmantes y defensores de convenios para reforestar los comunales en la provincia de Lugo, por ejemplo, se refería al monte objeto de su interés repoblador con la más que significativa expresión de "zona forestal donde no existe arbolado". ${ }^{17}$ Definen el monte, por tanto, como un espaçio a la espera de alcanzar su verdadera dedicación, su vocación, tarea de la que se erigen responsables.

Los ingenieros de los años cuarenta proyectan, al igual que lo habían hecho sus predecesores un siglo antes, en el monte español en general, y gallego en particular, la imagen de su "ideal forestal", un bosque con árboles de turno corto destinado a la producción de madera. Al igual que en el resto de Europa, en España la ciencia forestal alemana había dejado una fuerte impronta. ${ }^{18}$ Los primeros ingenieros forestales españoles habían cursado estudios en "ciencia forestal" en Alemania bajo el influjo de Georg Luwding Hartig y Heinrich Cotta, el padre de la Dasometría y fundador de la archifamosa Academia de Tharandt, y, a su vuelta, ocuparon los puestos de la Administración forestal recién creada en España e influyeron en la formación de las nuevas generaciones de ingenieros a través de su magisterio en la.Escuela de Montes de Madrid. La idea de crear un "forestal" en el monte no tiene que ver únicamente con una precisión conceptual desde el punto de vista técnico, sino que refleja un nuevo modo de uso, un cambio en el tipo de relaciones entre sociedad y explotación de recursos. Imbuidos de los principios de la Dasometría germana, aunque con discusiones internas sobre la naturaleza de la selvicultura a seguir, los ingenieros forestales españoles establecieron la generación y conservación de recursos forestales como las líneas maestras que debían seguir la gestión del monte español. ${ }^{19}$

\footnotetext{
${ }^{16}$ Iñaki Iriarte Goñi, "La obra de Octavio Elorrieta (1881-1962). El monte al servicio de la economía”, Historia Agraria 48 (2009): 133.

${ }^{17}$ Fondo Documental de la Delegación Provincial de Medio Ambiente en Lugo. Sección de Montes. Consorcios Cancelados.

${ }^{18}$ Gloria Sanz Lafuente, "Naturaleza y ciencias forestales en Alemania", Cuadernos de la Sociedad Española de Ciencias Forestales 16 (2003): 161-166.

${ }^{19}$ Sobre las influencias y el papel de estos ingenieros, Vincenç Casals Costa, Los ingenieros de montes en la España Contemporánea 1848-1936 (Barcelona: Ed. del Serbal, 1996); J. D. García Pérez, "The promotion of participation in planning
} 
Principios rectores que iban en contra de las características básicas del monte comunal gallego. ${ }^{20}$ Los montes son vistos como auténticas despensas de las grandes industrias celulósicas y madereras.

El ideal forestal convirtió la actividad de la administración forestal en un terreno para la construcción identitaria y el patriotismo. ${ }^{21}$ Salvador Trueba, en 1943 Director General de Montes, señalaba que era: "antisocial, antinacional importar una sola tonelada de madera que el país pueda producir". Estas palabras estaban en la misma línea de pensamiento que las de Demetrio Carceller cuando afirmaba que era necesario "ponerse a salvo de las onerosas servidumbres del extranjero", llevarán a que en ese mismo año se declarase la industria de celulosa como industria de interés nacional. En sus comentarios se evidencian varios elementos que estarán presentes en la práctica totalidad de la documentación forestal de los años cuarenta: la reforestación se hace por el bien de la nación, a la que el conjunto del proyecto repoblador favorecerá en términos económicos. Esta idea, repetida hasta la saciedad, entroncaba firmemente con el ideal autárquico que la economía franquista pregonaba, pero no solo se incidía en ella por "alinear" los intereses de la Administración forestal con el de la política económica estatal. ${ }^{22}$ Resaltar que el beneficiario de la labor repobladora era la nación suponía también asegurarse un argumento (que entendían invencible) en su liza contra las comunidades rurales. En "sus" manos estaba el bienestar de la nación, en genérico, un sujeto mucho más importante (en todos los niveles, número y entidad) que aquellos propietarios que no alcanzan a comprender la entidad de la empresa repobladora, pero a los que ellos abrirán los ojos cuando repartan los beneficios de la corta de madera. En ese momento entenderán que ellos también son parte de la nación beneficiada. La línea discursiva se completa cuando incide en la bondad, intrínseca, de beneficiar a "todos" frente a "unos pocos", esos que sería los únicos que sacarían cierto partido si los montes siguieran sin estar repoblados con especies arbóreas cuya corta en plazos cortos. Por la necesidad de completar esta "misión" (no un trabajo cualquiera, nótese el mesianismo y el sustrato militar) de velar por la nación y sus intereses se abunda en algunos textos en la idea de que los ingenieros de montes están llevando a cabo una "guerra moral". Elevan así su cometido a una esfera equivalente a la que habría definido de "cruzada" a la contienda civil, recubren, en este caso concreto, de valores un asunto específicamente económico como era la repoblación forestal.

A la vișta de los principales aprovechamientos de ambas espécies no hay duda de que proyectando en el momento actual y no habiéndose llegado a ejecutar todavía en la extensión suficiente para que junto al aprovechamiento existente surtir el día de mañana

for soil and water conservaion through reforestation: a case study of Guadalajara (Spain)" en Charles Watkins, ed., European Woods and Forest. Studies in Cultural History (Cambridge: Cambridge University Press, 1998): 191-213.

${ }^{20}$ Grupo de estudios de historia rural, "Diversidad dentro de un orden. Privatización, producción forestal y represión en los montes públicos españoles, 1859-1926”, Historia Agraria 18 (1999): 129-178.

${ }^{21}$ Alberto Sabio Alcutén, "Imágenes del monte público, 'patriotismo forestal español' y resistencias campesinas, 18551930" en Alberto Sabio Alcutén, ed., Naturaleza y conflicto social, Ayer 46 (2002): 123-133.

${ }^{22}$ Baste saber que la producción actual de madera en España es de poco más de un millón de metros cúbicos anuales, existiendo un déficit de unos tres millones de metros cúbicos para cubrir las necesidades actuales de consumo. Por otra parte el extraordinario desarrollo que han adquirido, con el progreso de la técnica, las industrias derivadas de la madera, hace prever que cada día será mayor la demanda de dicha materia prima. Este es precisamente el problema que actualmente se plantea en relación con nuestra economía forestal. Es un hecho indudable que lo que producimos no basta para satisfacer las demandas de nuestra industria respecto a una materia prima tan esencial como es la madera. Por otra parte en la actualidad hay grandes dificultades para abastecerse en el extranjero ... vemos nuestro déficit actual ... de unos tres millones de metros cúbicos ... lo que supone un peso exorbitante para nuestro comercio exterior, o la ruina de los montes particulares que aún nos quedan...'. Extracto de La repoblación forestal en la provincia y su aspecto ante las haciendas municipales. Discurso pronunciado por el Ingeniero del Servicio de la Repoblación forestal de Consorcio de la Excma. Diputación de Lugo con el Patrimonio Forēstal del Estado, en la Asamblea Municipalista provincial celebrada en Noviembre de 1945, por inicjativa del Gobernador Civil, p. 3-4. 
el mercado nacional de la madera y celulosa precisa tiene más justificación el pino rodeno como masa climácico-forestal que el abedul, [...] tanto más, cuanto por las condiciones de cómo se efectúan las repoblaciones en estos Consorcios con crecida participación en los aprovechamientos para las Entidades propietarias de los terrenos, las cuales sostienen verdaderas luchas morales con los paisanos de las parroquias a que los montes pertenecen por haberlos cedido a este fin, hay que dar preferencia a las especies de crecimiento rápido y aprovechamiento a turnos cortos en las primeras repoblaciones a fin de que obtengan cuanto antes el fruto de las aportaciones y experimenten con hechos y obras los grandes fines nacionales, económicos y sociales y los grandes beneficios que particularmente a ellos les reporta.

Por otra parte con la repoblación forestal no solamente se crea una riqueza para España de la cual y según la base 12 serán los vecinos los primeros beneficiados, pues el Patrimonio Forestal del Estado cederá a los propietarios del suelo el $40 \%$ de los beneficios que obtengan del aprovechamiento y explotación del vuelo arbolado sino que seguirán percibiendo gratuitamente los aprovechamientos de matorral, pastos y leñas muertas, (del que hoy carecen) según la misma base. ${ }^{23}$

El conjunto de los documentos consultados repiten uno, todos o varios de estas ideas fuerza relativas al bien nacional. Pero como puede verse en los extractos anteriores, hay otras argumentaciones recurrentes. Por ejemplo, la del provecho que para los pueblos traería la repoblación. Esta noción se expresa de varias maneras, una en términos de beneficio obtenido de la corta de madera, como hemos visto en el caso comentado previamente, otra aludiendo a los jornales que pagará la Administración a aquellos vecinos que trabajen en las labores de repoblación. En 1942, el ingeniero Ignacio Claver Torrente al redactar uno de sus proyectos de repoblación en un monte de la provincia de Lugo, va más allá y señala que no solo habrá ulteriores ventajas, sino que no habrá perjuicios para los vecinos en los trabajos de repoblación forestal de su monte. El técnico señalaba que podrían seguir cultivando cereal en ciertas parcelas a las que la repoblación no afectara de manera inmediata:

\begin{abstract}
[...] por una parte con los jornales en su ejecución, por otra permitirles que vayan recogiendo cosechas, que a la vez de la siembra del centeno hagan la de pino, con la semilla que se les entregue, en los sitios que a tal fin se les permite próximos a las parroquias y lugares y que conforme paulatinamente vayamos incorporando a lo repoblado las hectáreas sembradas por este medio gratificarles a los que las han ejecutado con una cantidad que presupuestamos aproximadamente igual a la de la preparación del terreno."24
\end{abstract}

No es lo habitual pero tampoco es la única excepción. Otro consorcio insiste en esta misma idea de los beneficios para las poblaciones locales, señalando que,

[...]durante el tiempo que dura la repoblación se han invertido solamente en jornales unas 150.000 pesetas, que han quedado entre los vecinos de este municipio; posteriormente esos mismos vecinos se han beneficiado con las cortas intermedias y durante todo ese tiempo han podido seguir practicando en el monte los aprovechamientos usuales, excepto el pastoreo, que habrá

\footnotetext{
${ }^{23}$ Archivo Histórico Provincial de Lugo (en adelante, A.H.P.L.) Documentación procedente de la Delegación Provincial de Agricultura. Sección San Breixo. Sig. 11.320-11.322.

${ }^{24}$ A.H.P.L. Documentación procedente de la Delegación Provincial de Agricultura. Sección San Breixo. Sig. 11.320-11.322.
} 
quedado vedado durante los cinco o seis primeros años, y que por las condiciones en las que se ejecutan estas repoblaciones; dispondrá en otros montes o en zonas no repobladas del mismo de extensión sobradísima para sus necesidades. ${ }^{25}$

Vemos como los ingenieros inciden en la gratificación económica como elemento que solventará el conflicto con los pueblos, pero se apartan de la norma al señalar que puedan seguir disfrutando de algunos de sus usos tradicionales (cosecha de cereal en uno de los casos y pastoreo de ganado en otro) y uno de ellos incluso asumirá la argumentación dada por los paisanos "según ellos si las necesitan [las cosechas] son por las actuales circunstancias que ha impuesto la guerra universal". La mayoría niega la posibilidad de cualquier uso tradicional una vez la administración forestal ha firmado el consorcio, como se comprueba en el siguiente fragmento:

[..,] ruego a V.E. tenga a bien ordenar la prohibición rotunda de que se deje entrar en el monte citado ganados de todas clases con el pretexto de pastoreo, así como ordenar a los agentes dependientes de la Autoridad de V.E. eviten con el máximo celo [...] todo acto que se realice contra la repoblación, que es uno de los puntales de la economía nacional. ${ }^{26}$

Como hemos visto en uno de los anteriores extractos discursivos, los ingenieros añadían comentarios que trataban de restar transcendencia a la necesidad que los vecinos tenían del monte que se va a repoblar, lo que redundaba en negar que las muestras de conflictividad de la población tuvieran algún tipo de razón. En los convenios se señalaba que "todas las parroquias tienen más monte y superficie a sus necesidades agrícolas y ganaderas del que el Ayuntamiento ha aportado al Consorcio" si bien en algunos documentos se reconoce "aunque algunos lugares de las mismas no les quede tan próximo como este" o haciéndose eco de que afirmaciones del tipo:

\begin{abstract}
Hoy en día existe en la Provincia extensión holgada de terreno, para poder acometer con intensidad esta clase de trabajos [de repoblación] sin que se derive perjuicio ninguno para la agricultura y la ganadería. ${ }^{27}$

Pero además y aparte de más monte de los àportados al Consorcio que la parroquia puede seguir disfrutando, se han dado y se siguen dando en cuantas repoblaciones se han ejecutado en la provincia toda clase de facilidades para que las necesidades de los vecinos no sufran en lo más mínimo, cual es por ejemplo el que sigan recogiendo matorral aún en la parte recién repoblada y en las superficies dedicadas a cortafuegos y en no extender la repoblación a toda la cabida del monte para que siempre tengan terreno suficiente y el repoblar esta parte inculta cuando dicho pastoreo pueda verificarse en el repoblado. ${ }^{28}$
\end{abstract}

\footnotetext{
${ }^{25}$ A.H.P.L. Documentación procedente de la Delegación Provincial de Agricultura. Sección San Breixo. Sig. 11.320-11.322.

${ }^{26}$ Escrito remitido por el Ingeniero Director del Consorcio al Gobernador Civil de Lugo en julio de 1943 después de que el Juzgado de $1^{\text {a }}$ Instancia de Lugo reconociera la posesión de los montes a los vecinos. Xunta de Galicia. Delegación provincial de Lugo de Montes e Industrias Forestais. Consorcios e Convenios de Guntín. Expediente del consorcio do monte Ladairo.

${ }^{27}$ La repoblación forestal en la provincia y su aspec̄to ante las haciendas municipales. Discurso... op cit.

${ }_{28}^{28}$ A.H.P.L. Documentación procedente da Delegación Provincial de Agricultura. Sección San Breixo. Sig. 11.320-11.322.
} 
Las afirmaciones de los forestales parecen dar por hecho que sería factible el "recolocar" los usos tradicionales del monte en la superficie de otro pueblo, ayuntamiento o haciendo caso omiso de los derechos de propiedad exigibles. El discurso positivo sobre la repoblación, llega a afirmar que a ni se les "ha privado a los vecinos de la riqueza ganadera, ni del suministro de leña, ni enajenado los montes."

Esos mismos convenios y otros muchos revisados explican la prohibición o reducción al máximo de las tareas del aprovechamiento agrosilvopastoral no solo, como cabría esperar, por una posible incompatibilidad de dichos usos con el forestal intensivo que pregonan, o por los daños que alguna de esas tareas pudiera suponer para la repoblación. A esos razonamientos les acompaña o incluso sustituye una reflexión ciertamente más tendenciosa que insiste en lo infructuoso de los trabajos de los vecinos en el monte. Se desmerecen los usos tradicionales achacándoles la condición de ineficaces e infructuosos a los rendimientos que obtenían. Son una pérdida de tiempo y trabajo, discurso contrario al de la absoluta necesidad que enarbolaban las comunidades.

porque estos terrenos son forestales aptos para estas especies [coníferas] y no para las agrícolas... muy superiores a esas roturaciones infructuosas y esquilmantes, con malas cosechas de centeno, que además de producirse cada 20 o 25 años en el mismo sitio no rinden el trabajo que les cuesta (espacio de tiempo en el que el vuelo arbóreo creado supone una gran riqueza en una materia que precisa España, mientras que de esta forma es un terreno inculto, pudiendo hacer por otra parte estas roturaciones en los montes que les quedan no aportados al consorcio y en los aportados y no iniciados para ejecutar su repoblación). ${ }^{29}$

En este punto, para consolidar su argumento, los ingenieros recurren muy usualmente a enumerar los efectos negativos que dichas labores han supuesto para el monte:

La pobreza del suelo, considerada como modificación sufrida en el medio por la acción anticultural del hombre en la tala de las antiguas masas, en las roturaciones esquilmantes y el pastoreo, a que someten este terreno impropio para este fin [...]. No ofrece duda que para iniciar la repoblación en este terreno desarbolado desde tiempo inmemorial y degradado tenemos [...] por conseguir las más convenientes masas bajo el aspecto silvícola, verdaderas masas.

Estas tesis han sido desmentidas, al menos como, verdades "universales" por el geógrafo francés Abel Bouhier y por la historiadora modernista Ofelia Rey que han estudiado los periodos medios entre dos roturaciones del monte. La autora señala que en el monte cerrado de primera calidad estos eran de 21 años, 28 en la segunda y 34 en la tercera, mientras que en los montes abiertos el ritmo medio era de 27,4 en los mejores terrenos, 36,5 en los medianos y 41 en los inferiores. Rey insiste en que la escala de frecuencias era siempre más amplia en este último tipo de montes, por lo general, situados en terrenos más altos y áridos y menos productivos, lo que vendría a suponer que los ritmos estaban

\footnotetext{
${ }^{29}$ Fondo Documental de la Delegación Provincial de Medio Ambiente en Lugo. Sección de Montes. Consorcios Cancelados.
} 
adaptados a las condiciones del terreno. ${ }^{30}$ La insistencia en la pobreza de los suelos a repoblar no era pues gratuita, y no se reducía a servir de argumento en contra del cultivo del monte para el cereal, sino que iba también encaminada a negar la pertinencia de otro de los usos más importantes para las comunidades, el pastoreo. José Luque apuntaba que los montes de la provincia de Lugo, tradicionales sustentadores de una importante cabaña ganadera eran:

montes sin ninguna riqueza arbórea, aptos solamente para un mal pastoreo, sin leña y como único aprovechamiento el del matorral... podemos generalizar que la variación que con la despoblación forestal ha experimentado la vegetación herbácea de esta provincia como consecuencia de desarrollarse en un medio más pobre y luminoso ha actuado sobre la vitalidad de la ganadería y puesto que el crecimiento y vigor de un vegetal son funciones de la sustancia que encuentra en pequeña cantidad en el suelo, su composición elemental se ha modificado y el animal que allí se nutre ha sufrido los efectos de la influencia de la composición de las materias útiles; y así es preciso hacer notar que en esta provincia, de terrenos graníticos en su inmensa mayoría, donde falta la cal y el ácido fosfórico, los ganados han ido percibiendo del suelo que les nutre en menor escala cada vez los elementos necesarios a la constitución de su esqueleto y en estas condiciones la talla quedó reducida y degenerada.

La preocupación por la conservación de los recursos forestales hizo que los ingenieros tildaran de "prácticas degradantes" o "causas de deforestación" a usos campesinos intemporales como eran las roturaciones para el cultivo de cereal, el pastoreo de ganado o la recogida de leña. Por tanto, los usos tradicionales fueron en muchos casos tipificados y condenados como "delitos" en el nuevo modelo de gestión forestal que se imponía desde la Administración. ${ }^{31}$ Los bajos niveles de productividad agraria se usaban como una prueba inequívoca de atraso, sin tener en cuenta otros parámetros como el valor nutricional o la eficiencia energética. De este supuesto "atraso" se derivaban otras patologías como la ignorancia campesina o su inmovilismo en múltiples aspectos (innovación tecnológica, política, etc.). ${ }^{32}$ Así, insiste en la incapacidad de las comunidades rurales gallegas para ver "lo que les conviene" y los beneficios que llevaba aparejada la repoblación de sus montes comunales. La argumentación de alguno de los consorcios extractados nos parece relevante porque nos evidencia ese aspecto del discurso forestal franquista. Si las comunidades pudieran entender lo que supondría la orientación forestal no mostrarían más que adhesión y colaboración para con su labor repobladora. En su mayoría los ingenieros asumen esta "ignorancia" e "incapacidad" de la población rural (que evidencian reiterando que trabajan el monte a cambio de míseras producciones) ${ }^{33}$ y creen que solo la represión

\footnotetext{
30 Ofelia Rey Castelao, Monte y política forestal en la Galicia del Antiguo régimen, (Santiago de Compostela: Universidade de Santiago de Compostela, 1995); Abel Bouhier, Galicia: ensaio xeográfico de análise e interpretación dun vello complexo agrario (Santiago de Compostela: Xunta de Galicia, 2001) [original: La Galice: Essai geographique d'analyse et d'interpretation d'un vieux complexe agraire, (Poitiers: Université de Poitiers, 1979).

${ }^{31}$ Un conversión la de las prácticas tradicionales en transgresiones de la legalidad magníficamente analizada para el caso andaluz en Salvador Cruz Artacho, "De campesino a ladrón y delincuente en Andalucía (XIX-XX). Otra mirada a la esfera de los comportamientos sociales del campesinado", en Antonio González de Molina, ed., La historia de Andalucía. A Debate. 1. Campesinos y Jornaleros (Barcelona: Anthropos, Diputación Provincial de Granada, 2000): 159-178.

32 Una idea de atraso que ha estado presente a manera de tópico hasta no hace mucho en los estudios de historia agraria. Una crítica exhaustiva a la misma en Ramón Garrabou et al., El pozo de todos los males: sobre el atraso de la agricultura española contemporánea (Barcelona: Crítica, 2001).

${ }_{33}$ estos montes cedidos, turbosos edafológicamente considerados, en etapa bastante avanzada y pobres, presentan como única vegetación principalmente ericas (principalmente la cincerae y umbelleta), y ulex minor, y en el proteretum una vegetación inferior de líquenes; que es todo el pasto y leñas que los vecinos creen tener... esta pobreza de suelo dada por el análisis es también indicada por la abundancia de brezos que es un signo de decaimiento de la capacidad productiva
} 
(multas, prohibiciones) o futuros beneficios económicos podrán "abrir sus ojos". ${ }^{34}$ No hubo ningún intento serio por acercar posturas ni por "negociar" ambas posturas. Tanto en el XIX como, sobre todo en el franquismo, la postura de las comunidades fue menospreciada a todos los niveles. ${ }^{35}$ Así pues, al conflicto generado por las diferentes lógicas debemos aunar para entender en toda su complejidad la conflictividad medioambiental, la manera de proceder de la Administración forestal. Ésta por toda respuesta ante las quejas de las comunidades rurales insistía en lo benévolo de su actuación reforestadora para éstas, así como en su falta de información y formación, que les impedía reconocer las ventajas de que su comunal se viera cubierto de coníferas de turno corto.

Patrimonio cederá a los propietarios del suelo el $40 \%$ de los beneficios que
obtenga del aprovechamiento [...] se dieron y se siguen dando en cuantas
repoblaciones se ejecutaron en la provincia toda clase de facilidades para que
las necesidades de los vecinos no sufran ni lo más mínimo, como por ejemplo,
que sigan recogiendo esquilmo incluso en la parte recién repoblada y en las
superficies dedicadas a cortafuegos y en no extender la repoblación a toda la
cabida del monte para que siempre tenga terreno suficiente y repoblar esta
parte inculta cuando dicho pastoreo pueda verificarse en el ya repoblado...
podemos decir que esta instancia, como otras llegadas para lnforme de esta
Dirección de los vecinos de parroquias próximas a cuantos montes se han
ejecutado repoblaciones, son firmadas sin conocer el verdadero espíritu de
quien las redacta o de quien asesora en la redacción, que es el que
propagando infundios irreales y tendenciosos, contrarios por completo al fin
que se persigue, pretende de esta forma defender unos ferrados de tierra que
ha cercado ha pocos años (23 ferrados equivalen a una hectárea en general en
esta provincia) al objeto de adueñarse de la propiedad comunal con el
transcurso de los años... Considerando que en iguales circunstancias se
encuentran cuantos vecinos gallegos, pues. todos están sometidos a
condiciones de vida común, en cuyas parroquias están sitos los montes ya
repoblados de los cuales subsisten en mejores condiciones que antes de
ejecutar estas repoblaciones con los jornales en la repoblación, en la
explotación, en las industrias creadas a la sombra de estas masas forestales,
con los aprovechamientos que siguen disfrutando (matorral), mejorándose los
pastos, creándose otros nuevos (leñas muertas, $40 \%$ de los beneficios de la
explotación, etc.). ${ }^{36}$

del suelo por ausencia de hojarasca protectora del mismo contra la acción desecadora de los vientos y del sol... el suelo es pobre y no hay pasto espontáneo'

${ }^{34}$ En este aspecto no había unanimidad entre los forestales, pues alguno de ellos no estaba de acuerdo con la represión como método aleccionador. Era el caso de Alfonso Acebal, ingeniero Jefe de la provincia de A Coruña en su ponencia en el Congreso Agrícola de Galicia, en 1944: '... [las repoblaciones] han de tener un marcado carácter de acomodación a las necesidades y costumbres del campesino y limitar en este sentido las presiones más o menos coercitivas que pudieran parecer adecuadas, ya que la experiencia nos enseña con frecuencia como se malogran los resultados de la labor emprendida sin la aquiescencia de los que directamente viven del campo'. Rico Boquete, 1995.

35 Todos aquellos ingenieros que, como Antonio Fenech en el último cuarto del siglo XIX, trataron de conciliar ambas lógicas o, cuando menos, tener presente las necesidades de las poblaciones rurales, no fueron tomados en consideración o incluso vieron cómo se procedía a su relevo en los cargos Sobre Antonio Fenech y Artells, Ingeniero Jefe del Distrito Forestal Pontevedra- Coruña durante 18 años, Xesús Balboa López, "Estudio preliminar" en A propiedade comunal no século XIX (Santiago de Compostela: Xunta de Galicia, 1999), 7-54, 15-16, 27-28. Sobre la disparidad de criterios dentro del cuerpo de ingenieros, Eduardo Rico Boquete, "La actividad repobladora del Patrimonio Forestal del Estado en los años del 'desarrollismo' : un estudio sobre dos montes de Guadalajara (1959-1975)", Comunicación al XV Congreso de Historia Agraria de la SEHA, (Lisboa, 2016).

${ }^{36}$ Fondo Documental da Delegación Provincial de Medio Ambiente en Lugo. Sección de Montes. Consorcios Cancelados. 


\section{El discurso empresarial en los conflictos ambientales}

\subsection{Encrobas: una mina a cielo abierto}

La crisis energética mundial de 1973 provocó en España, entre otros efectos, un renovado interés por la explotación de los recursos mineros del propio país. El gobierno de la dictadura se apresuró a reorganizar el marco legislativo para su explotación. En el mismo año 1973 se promulgó una nueva ley de minas (Ley 22/1973, de 21 de julio) y se aprobó el Plan Nacional de Abastecimientos de Materias Primas y Minerales. Finalmente, en 1978, se promulgó el Reglamento General para la Minería. En Galicia, este auge se tradujo en la explotación de por lo menos una docena de nuevas minas (1977), así como en la intensificación de los trabajos de extracción en otras (de caolín, lignito, cuarzo, magnesio, cobre, estaño, plomo, cinc y pizarra). Los conflictos surgieron, fundamentalmente, a raíz de la expropiación forzosa de terrenos de uso agrario o forestal, la mayor parte de las veces de propiedad comunal. ${ }^{37}$

El punto de partida del conflicto ambiental de Encrobas (Cerceda, A Coruña), se sitúa en la compra (1974) por parte de FENOSA de los derechos de explotación de un yacimiento de lignito a cielo abierto. Para ello la empresa eléctrica creó una sociedad filial, Lignitos de Meirama S.A. (LIMEISA) al tiempo que lograba que el gobierno de la dictadura declarara de "utilidad pública" e "interés preferente" el emplazamiento físico de la mina, con lo que la empresa quedaba autorizada a la expropiación forzosa por procedimiento de urgencia de los terrenos precisos para poner en marcha la explotación. El carbón de Encrobas estaba destinado a alimentar a la vecina central térmica de Meirama (en el mismo municipio coruñés de Cerceda) que se abriría de forma simultánea a la puesta en explotación de la mina. A comienzos de 1976 se produjeron los primeros contactos entre Lignitos de Meirama S.A. y los vecinos de la parroquia de Encrobas afectados por la mina, con el fin de llegar a un acuerdo sobre el valor a pagar por las propiedades expropiables. Los vecinos rechazaron la oferta inicial de la empresa por considerarla económicamente insuficiente. ${ }^{38}$

En un contexto político tan particular como el que hemos descrito, el conflicto pronto cobró una nueva dimensión, fundamentalmente porque las reivindicaciones de los vecinos afectados contaron con el apoyo de una amplia nómina de aliados externos social y políticamente influyentes, entre los que habría que destacar a las organizaciones políticas y sindicales vinculadas al nacionalismo gallego, así como a un grupo de activos sacerdotes rurales. La negativa de la mayoría de los vecinos de Encrobas a aceptar las compensaciones ofrecidas por Lignitos de Meirama SA - FENOSA, así como la iniciativa colectiva - aprovechando un resquicio de la ley de expropiación forzosa - de exigir a FENOSA el traslado de toda la comunidad a una localización física, productiva y paisajística lo más parecida posible a Encrobas, enquistó el conflicto y permitió a los labradores ganar tiempo para presentar su situación a la opinión pública y fortalecer una posición estratégica a priori débil.

Sin embargo, el salto cualitativo en la escala de este conflicto ambiental vino de la mano de la decisión de la empresa (con el apoyo de la administración del Estado) de hacer que se cumpliera por la fuerza el expediente de expropiación forzosa. Las fuerzas del orden (en este caso la Guardia Civil) intentaron en hasta tres ocasiones (septiembre y noviembre

\footnotetext{
${ }^{37}$ Ana Cabana, Alba Díaz, Daniel Lanero, André Taboada y Víctor Santidrián, "Dinámicas políticas de la sociedad rural gallega: entre la agonía de la dictadura y la implantación de la democracia (1970 - 1978)", Historia del Presente 21 (2012): 123-144.

${ }^{38}$ Sobre el conflicto de Encrobas, véanse: Nieves Herrero, "Paisajes de una mina a cielo abierto' en Los últimos mineros. Un estudio antropológico sobre la minería en España,( Madrid: CIS, 2002): 169-231; Daniel Lanero, "Comunidad rural, conflicto socioambiental y organizaciones políticas̄ en la Galicia de la transición. El caso de As Encrobas, 1976 - 1977 " HALAC II(2): 160-196.
} 
de 1976 y febrero de 1977), ocupar el monte vecinal Pau Rañón, a lo que los vecinos se opusieron sistemáticamente, produciéndose episodios de gran tensión hasta que el 15 de febrero de 1977, tras cerrar los accesos al monte, desarmar (de hoces, palos, martillos y paraguas) a los comuneros y detener uno a uno a los labriegos resistentes, la ocupación física (condición sine qua non para la expropiación) se hizo efectiva.

Finalmente, el conflicto entró en la vía institucional terminando por resolverse en el verano de 1977, obteniendo los vecinos afectados por las expropiaciones unas indemnizaciones mucho más elevadas que las inicialmente ofrecidas por la empresa, así como que esta asumiera otros compromisos, como la prioridad en la contratación de vecinos afectados como mano de obra del complejo industrial o el pago de pensiones vitalicias para los más ancianos.

Entre tanto, los ecos del conflicto habían alcanzado no sólo toda Galicia, sino también al conjunto de la opinión pública española. Los medios de comunicación (en especial la prensa escrita gallega, pero también las principales cabeceras españolas e incluso alguna TV extranjera) habían ofrecido una cobertura muy detallada del conflicto y funcionado como altavoz para los argumentos tanto de los perjudicados por la futura mina y de sus apoyos sociales y políticos como de los discursos de la empresa y de la Administración pública. ${ }^{39}$ La rápida e intensa repercusión que el conflicto de Encrobas adquirió en los medios de comunicación, sobre todo en los diarios gallegos, en los que se convirtió en noticia habitual desde la primavera de 1976, cogió por sorpresa tanto a Lignitos de Meirama S.A. como a su empresa matriz, FENOSA, como evidencia el retraso con que el grupo empresarial transmitió su visión del conflicto a la opinión pública gallega.

Una vez que FENOSA fue consciente de la dimensión que estaba tomando el conflicto, de la habilidad con la que los afectados y sus aliados externos estaban sensibilizando a una parte importante de la opinión pública en favor de sus demandas y, en definitiva, del daño que estaba sufriendo su imagen como corporación ante el conjunto de la sociedad gallega, optó por jugar un papel más activo en la escena pública, articulando un discurso propio que sirviera tanto para explicar su postura como para confrontar sus argumentos con los de los colectivos que se oponían al proyecto industrial Encrobas - Meirama.

Para ello, la empresa diseñó una estrategia de comunicación, de la que aquí destacaremos tres elementos principales: los comunicados o notas oficiales a la prensa (al menos tres entre finales de 1976 y el otoño de 1977); los editoriales y columnas de opinión publicados en su revista corporativa, Kilovatio y, finalmente, la reproducción, en esta misma publicación, de artículos tomados de la prensa generalista española que defendían enfoques coincidentes con los de la propia compañía. El análisis pormenorizado de estos tres tipos de fuente hemerográfica nos ha permitido identificar una nómina de temas y argumentos a partir de los cuales LIMEISA - FENOSA articuló su discurso público a lo largo del conflicto.

La cuestión del daño a su imagen fue un asunto especialmente preocupante para FENOSA. A este respecto es importante tener en cuenta la omnipresencia de la empresa en el contexto político y económico de la Galicia del franquismo. ${ }^{40}$ FENOSA no sólo había sido fundada en A Coruña en 1943 por un amigo íntimo del general Franco, Pedro Barrié de la

\footnotetext{
${ }^{39}$ En defensa de los labradores de Encrobas se articuló un amplio movimiento social del que participaron casi todas las organizaciones políticas y sindicales de la oposición democrática nacionalista y de izquierda, así como numerosos colectivos de la sociedad civil que se encontraban en plena efervescencia organizativa (asociaciones de estudiantes y culturales, de trabajadores, de amas de casa, colectivos profesionales o determinados sectores de la iglesia gallega).

40 Jordi Nadal, Xan Carmona, Galicia industrial (c.1750 - 2006) (A Coruña: Fundación Pedro Barrié de la Maza, 2005), 272284; Ana Cabana, Daniel Lanero, "Movilización social en la Galicia rural del Tardofranquismo (1960 - 1975)", Historia Agraria 48 (2009): 111-132.
} 
Maza, con capitàl gallego, sino que disfrutaba de una posición cuasi monopolística (controlaba en torno al 90\%) en el abastecimiento del mercado gallego de energía eléctrica. ${ }^{41}$ Además, con el telón de fondo de la crisis del petróleo y de las elevadas necesidades eléctricas que se calculaban para posibilitar el "deseado" desarrollo industrial español, la empresa tenía, en la década de 1970, enormes expectativas de expansión a corto y medio plazo, tal y como demuestran proyectos de la envergadura de la construcción de una central nuclear en Xove (Lugo) o el propio conglomerado minero - energético constituido por la mina de lignito de Encrobas y la vecina central térmica de Meirama. No por casualidad, las varias notas oficiales que Lignitos de Meirama S.A. remitió a la prensa gallega tenían como objetivo explicar su postura en el conflicto ambiental de Encrobas ante lo que la empresa entendía como una imagen errónea (malintencionada) de su actuación: "El largo proceso de trámites, conversaciones y negociaciones llevadas a cabo por la Empresa (...) han tenido una repercusión pública que, tras presentar una errónea imagen de esta sociedad." $" 42$

Lignitos de Meirama S.A. ha [difundido] una nueva nota oficial que de alguna
manera conteste desde dentro a la avalancha de escritos, comunicados y
acciones de protesta que desde fuera, con tan legítima voluntad de solidaridad
comó ignorancia de la esencial problemática del tema, se vienen prodigando en
periódicos y otros medios de comunicación social, amén de en la propia calle. ${ }^{43}$

Mucho más expresivo a este respecto era el editorial que abría uno de los números de Kilovatio: ${ }^{44}$

Se ha asomado a la actualidad de nuestra Sociedad, como una piedra imprevista y alevosa que ha intentado romper todos los cristales de nuestro prestigio, de nuestra imagen, de nuestro largo y denso historial de servicio y trabajo, un nombre ya famoso a lo largo y a lo ancho del país: As Encrobas. Un tema que nos convirtió, insólitamente, en una especie de oportuna y ocasional diana sobre la que se dispusieron a disparar sus flechas envenenadas gentes, grupos, partidos y éntidades. En un momento en que parece que el tema - el enfrentamiento de una gran empresa con unos campesinos que defienden sus tierras - se ofrecía como una especie de bombón para la voracidad demagógica que una recién estrenada libertad ha puesto en juego de desordenada circulación al que muchos medios de información se han

\footnotetext{
${ }^{41}$ La cuestión de la "galleguidad" de FENOSA y de su vocación de servicio público a Galicia y a los gallegos durante los treinta años precedentes, fue un lugar común en el discurso público de la compañía a lo largo del conflicto: "Pocos valoran nuestro servicio de treinta y tantos años a Galicia, donde nuestra empresa nació con hombres gallegos, con capital gallego, con instalaciones e inversiones gallegas, con mercado gallego..."; Kilovatio, 54, p.1; " (...) quienes arrecian contra una empresa gallega, fundada en momentos delicados y difíciles del desarrollo del país que hiciera [sic] posible un despegue industrial tan necesario e inaplazable como el que demandaba el país en los años cuarenta", Kilovatio 54, 20. 42 "Lignitos" no acepta la oferta de los vecinos de Encrobas". El Ideal Gallego. A Coruña, 5 de diciembre de 1976, p. 4; "Lignitos de Meirama, S.A. y las expropiaciones de terrenos en Cerceda". La Voz de Galicia. A Coruña, 5 de diciembre de 1976. En esta misma línea y en relación al grado de cumplimiento del acuerdo alcanzado el 12 de julio de 1977 entre LIMEISA y los afectados, véase: "La empresa está cumpliendo fielmente sus compromisos con los vecinos". El ldeal Gallego. A Coruña, 24 de septiembre de 1977.

43 "Lignitos de Meirama aceptó los precios fijados por una comisión". El ldeal Gallego (A Coruña, 20 de febrero de 1977), 9

44 "Pedrada a una imagen". Kilovatio. Revista de FENOSA 54 (marzo de 1977), 1. El título del editorial hacía referencia a los incidentes registrados en A Coruña durante una manifestación celebrada el 17 de febrero de 1977, dos días después del último (y más tenso) intento fallido de ocupación del monte Pau Rañón por parte de la Guardia Civil. En su transcurso varios manifestantes - concentrados ante la sede de FENOSA en A Coruña - rompieron seis lunas de la planta baja del edificio. La Voz de Galicia. A Coruña, 18 de febrerō de 1977 y El Ideal Gallego. A Coruña, 18 de febrero de 1977.

Concentraciones semejantes se produjeron por las mismas fechas en otras ciudades gallegas, como Vigo u Ourense.
} 
prestado traicionando, incluso, su propio emplazamiento doctrinal y a la indispensable objetividad a la que están ciertamente obligados (...) Lignitos de Meirama S.A. afrontó con serenidad esta avalancha de insultos, de acusaciones, incluso de premeditadas falsedades, recurriendo a explicar, donde pudo y como pudo, cual había sido su actitud, su postura (...). Pero era una voz prácticamente aislada, enfrentada a un tumulto, a un griterío, a una beligerancia ocasional tan mínimamente objetiva como para obligar a explicar, por la vía del informe "remitido", es decir, presentado como mera publicidad, a las páginas y páginas "informativas" con que periódicos y revistas se disputaron la brillantez demagógica del tema (.....45 Hemos sido diana de muchos disparos que han intentado deteriorar nuestra imagen y presentarnos como los malos de una elemental historia en la que se han mezclado muchos ingredientes sectarios y marginales que nada tienen que ver con nosotros, con As Encrobas, con la electricidad, con el servicio.

En la articulación de su discurso, LIMEISA - FENOSA conjugó una notable variedad de argumentos. Aunque empleados por lo general en un mismo nivel discursivo, tiene interés el hecho de que algunas de estas ideas - fuerza remitían a aspectos muy concretos, circunscritos a los orígenes y motivos del conflicto de Encrobas, a cómo este estaba evolucionando 0 a las posibles soluciones futuras al mismo. ${ }^{46}$ Entre estos la empresa apelaba a la obligatoriedad de prestar respeto a lo establecido por la ley de expropiación forzosa ${ }^{47}$ se quejaba del precio excesivo y constantemente revisado al alza que los labradores afectados solicitaban en forma de indemnización por las tierras expropiadas; criticaba la (supuesta) falta de representatividad (tanto en términos legales como sociales) de la Comisión de vecinos con la que negociaba una solución; llamaba la atención sobre el carácter artificial (político) del conflicto, al presentar ante la opinión pública la cantidad de acuerdos a los que había ido llegando con otros propietarios afectados, lo que a su vez le servía para destacar su firme voluntad negociadora y, para finalizar, esgrimía el argumento de la gran cantidad de empleos directos e indirectos que tanto la mina de Encrobas como la central térmica de Meirama generarían en la comarca: "(...) creándose con carácter permanente setecientos puestos de trabajo directos y más de mil quinientos indirectos, por efecto inductivo, según las estadísticas sobre este tipo de industrias." ${ }^{48}$

En el contexto del importante incremento del paro que la crisis del 73 provocó en España, la cuestión del empleo se convirtió en un argumento empresarial recurrente en el discurso de-las compañías involucradas en conflictos ambientales durante este periodo.

\footnotetext{
${ }^{45}$ El editorial critica la frecuencia con la que los medios de comunicación escrita reproducían de modo literal declaraciones, escritos o notas que recibían tanto de los vecinos afectados como de los numerosos colectivos sociales y profesionales que los apoyaron durante el conflicto. La empresa, consciente de que estaba perdiendo la batalla de la opinión pública, dio muestras de su disgusto ante la recién estrenada "libertad de prensa". Durante el segundo intento frustrado de ocupación del monte vecinal (noviembre de 1976), el director de LIMEISA, Francisco Rosado: "(...) se refirió con extrañeza al interés que mostraba la prensa sobre el tema, habiendo casos de expropiaciones todos los días. Hizo votos para que los periodistas contáramos la verdad", La Voz de Galicia (A Coruña, 27 de noviembre de 1976).

${ }^{46}$ Todos estos argumentos se pueden seguir en detalle a través de las notas oficiales remitidas por Lignitos de Meirama S.A. a la prensa: El Ideal Gallego. A Coruña, 5 de dičiembre de 1977; La Voz de Galicia. A Coruña, 5 de diciembre de 1977; El Ideal Gallego. A Coruña, 18 de febrero de 1977; El Ideal Gallego. A Coruña. 20 de febrero de 1977; La Voz de Galicia. A Coruña, 20 de febrero de 1977; así como en: "En torno al problema das Encrobas. Informe de "Lignitos de Meirama S.A.", Kilovatio, 54 (marzo 1977), 11.

${ }^{47}$ El argumento del respeto debido a la Ley de Expropiación Forzosa, así como el supuesto carácter ventajoso de los precios pagados por LIMEISA - FENOSA a los afectados, en "Politización de unas expropiaciones". ABC, Madrid (sin fecha conocida), artículo reproducido en Kilovatio, 54 (marzo de 1977), 12. El espíritu y la forma de aplicación de la Ley de Expropiación forzosa fueron cuestionados con frecuencia durante estos años. La empresa siempre invocó esta ley como un elemento neutral, sin hacer explícito que su aplicación en Encrobas derivaba, en último término, del acuerdo alcanzado con el Estado para la explotación del yacimiento (vid. infra).

48 "En torno al problema das Encrobas. Informe de "Lignitos de Meirama S.A.", Kilovatio, 54 (marzo 1977),-11.
} 
Otros argumentos, por el contrario, hacían referencia a problemáticas que podríamos denominar genéricas o estructurales en el contexto histórico de la transición a la democracia en Galicia y España. Entre estas últimas se pueden citar cuestiones como las consecuencias de la crisis del petróleo para el país; la nueva política energética con que el Estado pretendía hacer frente a la misma (y en la que las compañías eléctricas desempeñarían un papel muy destacado), las necesidades de producción eléctrica de Galicia o la cuestión de la utilización política de cualquier episodio de descontento social (incluidos los conflictos ambientales) por parte de las organizaciones de la oposición política y sindical al régimen ( $\mathrm{y}$ al primer gobierno de la transición como prolongación institucional de aquel) con el fin de forzar y acelerar la apertura del propio sistema político. ${ }^{49}$ Partidarios y detractores del incremento de la producción de electricidad en Galicia revistieron, a fin de dotarlos de mayor legitimidad, sus discursos de argumentos técnico - científicos de difícil comprensión para el conjunto de la población.

El renovado interés del régimen franquista por el carbón autóctono no se puede separar de los efectos de la crisis energética mundial. La dictadura pretendió modificar la dependiente estructura energética española con una serie de medidas, entre ellas un decidido apoyo a la explotación y transformación de carbón autóctono, que se concretó en el Concierto de la minería del Carbón (Decreto 2845 de 1974), por el cual las principales empresas energéticas españolas se comprometían a la modernización de sus infraestructuras y al incremento de su producción a cambio de beneficios fiscales. A finales de 1975 Lignitos de Meirama S.A. se acogió al Concierto, firmando un acuerdo con el Estado por el cual se comprometía a poner en marcha el complejo minero - eléctrico de Encrobas Meirama con fecha de primero de enero de 1979:

La importancia de la obra se hace patente con la simple alusión al problema energético que atraviesa el mundo, que ha obligado a todas las naciones al aprovechamiento de sus combustibles propios, incluso los de bajo poder calorífico, como son los lignitos (...). Consecuentemente se creó en España la Acción Concertada para la Minería del Carbón, firmándose con fecha de 26 de diciembre de 1975 un Acta de Concierto entre el Estado español y Lignitos de Meirama S.A. en la que se impone a este Sociedad la obligación de iniciar la explotación del yacimiento dentro de unos plazos fijados (...). Dada la urgencia que existía para acometer la obra, impuesta por la propia Administración, Lignitos de Meirama debería haber iniciado sin ninguna dilación el trámite de ocupación, pero antes prefirió recurrir a negociaciones con los propietarios, a fin de poder llegar a acuerdos voluntarios entre las partes. ${ }^{50}$

O en una línea argumental semejante:

\footnotetext{
${ }^{49}$ LIMEISA - FENOSA se quejó habitualmente de qủe la dimensión que había alcanzado el conflicto de Encrobas no respondía a las demandas de los afectados sino al hecho de que estaba siendo utilizado como pretexto para introducir en la esfera pública debates globales acerca de la economía de mercado o la autonomía política de la región a los que la empresa afirmaba la cuestión de Encrobas era ajena. Algunos medios de comunicación, en particular los más cercanos al gobierno, incidieron en esa misma línea argumental. Un buen ejemplo fue el guión del reportaje emitido por Televisión Española (TVE) en el programa de ámbito regional "Panorama de Galicia" de 25/371977: "El tema de As Encrobas comienza a hacerse aburrido, y detrás del problema humano empiezan a verse algunas manipulaciones. Los labriegos están siendo víctimas de intereses ajenos al problema (...) El tema de As Encrobas huele mal. Las víctimas serán pues los labriegos, los pobres labriegos manipulados y condicionados por unos intereses que no son los suyos".

${ }^{50}$ El ldeal Gallego. (A Coruña, 5 de diciembre de 1976); La Voz de Galicia. (A Coruña, 5 de diciembre de 1976); Kilovatio 54, 11.
} 
[La èmpresa] está obligada a cumplir unos objetivos que le son fijados por la propia Administración, precisamente al servicio de eso que ahora tanto se pregona como industrialización racional (...) en un momento en que la cuestión energética, derivada del encarecimiento internacional del precio del petróleo, es la gran protagonista de la crisis económica de Occidente, y el ahorro de divisas que esta obra supondrá para España es lo que le proporciona su carácter de utilidad pública. $^{51}$

La cuestión de la respuesta político-empresarial a la crisis del petróleo enlazaba de forma directa con el debate sobre las necesidades energéticas de Galicia a corto y medio plazo. FENOSA trató siempre de reaccionar con contundencia a un argumento por entonces muy habitual entre los sectores políticos e intelectuales críticos con el modelo de industrialización que el Estado estaba aplicando en Galicia: el carácter innecesario del aumento de la producción de electricidad en Galicia, pues la demanda regional estaba bien suplida y la mayor parte de la electricidad producida en Galicia se exportaba sin que su venta reportara un beneficio real para nadie más que para el propio capital empresarial. Un informe socio - económico sobre Encrobas encargado por un sindicato agrario a un "grupo de profesionales" afín a las organizaciones nacionalistas concluía que un 60\% de la electricidad producida en Galicia era exportada. FENOSA contraponía a este dato (que consideraba sin fundamento) una situación coyuntural (desde comienzos de la década de 1970) de importación de alrededor del 25\% de la energía eléctrica que se consumía en Galicia; la imposibilidad, ante la variabilidad pluviométrica, de garantizar el suministro a corto plazo confiando únicamente en la explotación hidroeléctrica de la red gallega de embalses y, por encima de todo, la imperiosa necesidad que la sociedad gallega tenía de que se concretasen sus dos proyectos estrella: el complejo Encrobas - Meirama y la central nuclear de Regodela (en Xove, Lugo). ${ }^{52}$

Como era habitual en la opinión pública de la época, toda la polémica en torno a Encrobas y otros conflictos ambientales coetáneos se enmarcaba, en último término, en el debate sobre el (ampliamente asumido) atraso económico de Galicia y la imperativa necesidad de modernización de sus estructuras productivas, es decir, de industrializar el país como única vía posible hacia su progreso material (económico) y social (casi nos atreveríamos a decir que también espiritual). A este nivel, las referencias al secular atraso de Galicia, al abrumador predominio de las actividades primarias, a la emigración como drama, etc. se conjugaban con el carácter imprescindible de la producción eléctrica para el desarrollo industrial del país:

\footnotetext{
[...] haciendo posible [FENOSA] cuanto ya existe en el país para su desarrollo e industrialización, porque la energía eléctrica es el punto de partida de cualquier proceso de desarrollo y cuanto ya se ha hecho es porque ha habido la energía necesaria (...). Es decir, FENOSA ha hecho siempre lo que había que hacer, en un país donde queda tanto por hacer (...) Galicia entera va a demandar esa mayor electricidad que siempre acompaña a un mayor índice de calidad de vida $^{53}$

Lo peor de todo es que lo que no se haga hoy difícilmente podrá recuperarse mañana, y el país no está para demasiadas inhibiciones y demoras. ${ }^{54}$

${ }^{51}$ El Ideal Gallego (A Coruña, 20 de febrero de 1977); La Voz de Galicia (20 de febrero de 1977).

52 "La verdad de la electricidad gallega". Kilovatio, 52 (septiembre de 1976), p. 1 - 2. En la misma línea véase el artículo de Javier Belderrain, "Los lignitos de Meirama. Regionalismo y Ecologismo", Informaciones, reproducido en Kilovatio 54, 13.

53 Kilovatio 54, 1.

${ }^{54}$ Ramón García Fontenla: "iSeñor, que largo me lo fiáis”, en Kilovatio 54, 20.
} 


\subsection{La Autopista del Atlántico}

La convocatoria en el Boletín Oficial del Estado de 2 de marzo de 1972, de un concurso público para la ejecución de un puente que salvara la Ría de Vigo, fue el punto de partida para la construcción de una autopista de $235 \mathrm{~km}$ que uniría de norte a sur, todo el occidente gallego. Un decreto del Ministerio de Obras Públicas de agosto de 1973 otorgó la construcción, conservación y explotación de la vía a Autopistas del Atlántico Concesionaria Española S.A. (AUDASA), una sociedad constituida ad hoc en 1973 con capital íntegramente financiero, aportado por las cajas de ahorro gallegas y por numerosos bancos del resto del Estado.

El plazo de ejecución previsto era de cuatro años, pero la construcción de la Autopista del Atlántico se demoró hasta comienzos del siglo XXI. Varias causas explican este gran retraso, pero sin duda la principal fue la fuerte oposición social que la empresa concesionaria encontró durante la segunda mitad de la década de 1970 en diferentes puntos a lo largo del trazado. Las protestas alcanzaron también los barrios periféricos de las dos principales ciudades de Galicia, Vigo y A Coruña, perjudicados por la manera en que la vía desembocaba en estas urbes. ${ }^{55}$

Los motivos del descontento de los afectados por la construcción de la Autopista del Atlántico eran semejantes en todos los focos rurales del conflicto. La construcción de la vía implicaba la desarticulación territorial de los espacios que atravesaba: las obras destruían la red viaria local de caminos y senderos; causaban destrozos en el sistema de abastecimiento de aguas y, en ocasiones, el uso de explosivos provocaba graves daños a las viviendas. La otra gran cuestión que alimentaba el malestar de los afectados (al igual que en Encrobas) era la forma en que la empresa se acogía a las posibilidades que le ofrecía la Ley de Expropiación forzosa. Los vecinos se opusieron de distintas maneras a la ocupación por la fuerza de sus tierras, al tiempo que expresaban su insatisfacción por lo exiguo de las indemnizaciones y ante los constantes retrasos en su pago por parte de AUDASA.

Como sucedió en Encrobas, las primeras manifestaciones conflictivas (marzo de 1977) se transformaron con rapidez en un movimiento social bien articulado contra la Autopista del Atlántico. De modo parecido, los afectados por la construcción de la autopista contaron pronto con una extensa e influyente nómina de aliados externos, entre los que cabe destacar al grupo de profesionales y expertos (arquitectos, sociólogos, juristas...) que constituyó el Círculo de Investigaciones y Estudios Sociales (CIES), dedicado al asesoramiento técnico de los afectados. A ellos hay que sumar parte de los "nuevos" medios de comunicación de masas, con un papel muy destacado de la prensa escrita y de sus reporteros gráficos, a la mayoría de las organizaciones políticas y sindicales de tendencia ideológica nacionalista e izquierdista y a toda una serie de colectivos de la sociedad civil. Así, en el verano de 1977 la confluencia de particulares y de asociaciones de vecinos de las zonas afectadas había dado lugar - bajo el impulso y control político de organizaciones nacionalistas gallegas - a una Coordinadora Nacional de Afectados por la Autopista del Atlántico. Como se puede ver, y no es de extrañar dada su coincidencia cronológica, la relación de aliados externos con los que contaban los afectados por la mina de Encrobas y por la construcción de la autopista era prácticamente intercambiable.

\footnotetext{
${ }^{55}$ La conflictividad alrededor de la construcción de la Autopista del Atlántico apenas ha sido tratada por la historiografía: Daniel Lanero, "Entre dictadura y democracia: la conflictividad social en las Rías Baixas (1959 - 1980)", Por surcos y calles. Movilización social e identidades en Galicia y País Vasco (1968 - 1980) (Madrid: Los Libros de la Catarata), 139-172; Carlos Punzón, "Autopistas del Atlántico. El largo camino del progreso", en Cristina Abelleira, ed., Grandes empresas, grandes historias de Galicia (A Coruña: La Voz de Galicia), 86-91. A modo de fuente: Xulio Sequeiros, Ceferino Díaz y Xaime Barreiro, A "Autopista del Atlántico". Sistema de transporte e desenrolo galego (Vigo: Galaxia, 1977).
} 
La construcción del discurso del movimiento social siguió también en el caso de las protestas contra la Autopista del Atlántico un itinerario semejante. Las reivindicaciones de los afectados por la autopista a lo largo de su trazado eran concretas y se expresaban en clave local: reposición de caminos y senderos, preservación de pozos y acequias, construcción de pasos elevados, pago de indemnizaciones justas por los terrenos expropiados... En sus demandas, los labradores afectados no cuestionaban la pertinencia o no de la autopista para Galicia, pero las consecuencias que su construcción estaba teniendo sobre su modo de vida y sobre las dinámicas comunitarias facilitaron un cambio de escala (de local a nacional) en el planteamiento del conflicto. A este respecto, hay que destacar el papel del Círculo de Investigaciones y Estudios Sociales, centrado en presentar a la sociedad gallega argumentos contrarios a la autopista, con el fin de entablar un debate público con la empresa y la Administración sobre la pertinencia o no de la construcción de la vía. Los expertos del CIES defendían una alternativa propia como solución al problema de las comunicaciones terrestres en Galicia, que consistía en potenciar el sistema ferroviario regional y desarrollar un esquema de carreteras radiales a partir de la red de carreteras nacionales existente. Para ellos (a diferencia de la interpretación que hacían AUDASA, la Administración y las organizaciones de empresarios gallegas), la autopista no era un factor de progreso, sino un acelerador de la desarticulación territorial del país, que dejaría a aldeas y pueblos aislados de los principales ejes de comunicación. Resuena tras estos argumentos, el eco que las teorías del colonialismo interior y de la dependencia económica habían alcanzado desde la década de 1960 entre los intelectuales y las organizaciones políticas nacionalistas y de izquierda. ${ }^{56}$

Las reivindicaciones de los afectados por la construcción de la Autopista del Atlántico fueron, en líneas generales, exitosas. La administración del Estado obligó a la empresa concesionaria a modificar notablemente el proyecto original y la cuantía de las indemnizaciones económicas recibidas por las expropiaciones se incrementó. La mejor prueba de ello era la decisión gubernamental (marzo de 1977) de paralizar durante un año y medio las obras en el más conflictivo de los tramos en construcción. Esta decisión se hizo extensiva en diciembre de 1979 a aquellos segmentos de la obra aún no iniciados, como colofón a más de dos años de aguda conflictividad, con importantes episodios de tensión entre los vecinos afectados y las fuerzas del orden. Entre tanto, el conflicto había alcanzado la escala regional y gran repercusión en la opinión pública. Todo ello en un contexto de construcción de un nuevo sistema político jalonado por varias convocatorias electorales (legislativas y municipales) y plebiscitos (constitucional y estatutario) entre 1977 y 1982.

AUDASA enfrentó la creciente y cada vez mejor organizada oposición a la Autopista del Atlántico con el empleo de diversas estrategias. La empresa llevó a cabo una intensa campaña publicitaria en defensa del interés de la obra para la sociedad gallega en los medios de comunicación. La propaganda empresarial fue constante a lo largo de todo el conflicto, acentuándose en las fechas que precedieron a las expresiones públicas más numerosas y mejor organizadas en contra de la autopista. ${ }^{57}$ Los principales periódicos gallegos, así como algunos otros de ámbito estatal, fueron también utilizados por AUDASA para transmitir a la opinión pública su posición ante las dificultades para el desarrollo del proyecto, rebatir los argumentos de los colectivos y organizaciones que se oponían a la prosecución de las obras de la autopista ${ }^{58}$, promover la creación de estados de opinión ${ }^{59^{\circ}}$ o

\footnotetext{
${ }^{56}$ Ramón Lopez, Cara unha visión crítica da economía galega. (A Coruña: Edicións do Rueiro, 1975).

${ }^{57}$ Así sucedió, por ejemplo, en las fechas entorno a la manifestación celebrada en Pontevedra en septiembre de 1977, en la que participaron entre 5.000 y 10.000 personas: "En reiterados y extensos espacios publicitarios pagados a los periódicos gallegos intentan [los representantes de Autopistas del Atlántico SA] demostrar estos días que su idea autopistera es la panacea para que Galicia entre en la modernidad". El País. Madrid, 15 de septiembre de 1977.

${ }^{58}$ El País. Madrid, 8 de octubre de 1977
} 
incluso presionar a algunas partes involucradas en el conflicto, en particular a la Administración, a la que la empresa amenazó veladamente con una posible reversión de las obras y con la solicitud de la correspondiente indemnización. ${ }^{60}$

En esta ofensiva publicitaria, las fotografías aéreas y los dibujos ("alzados") del puente sobre là Ría de Vigo, se convirtieron en una especie de icono que simbolizaba mejor que ningún otro los valores de progreso y modernidad a los que AUDASA asociaba la obra en su discurso público y con los que pretendía concienciar a los gallegos sobre sus bondades. En este sentido, las exigencias técnicas de la obra y el impacto visual de puentes, viaductos y otras grandes infraestructuras fueron celebrados por la concesionaria como una suerte de "nueva monumentalidad" vinculada al progreso de las comunicaciones.

Amparada políticamente por las elites de la dictadura y encarnando el discurso de la modernidad frente a la percepción de atraso secular del país ${ }^{61}$, la empresa se vio sorprendida por la proliferación de numerosas manifestaciones de descontento vecinal, así como por la veloz articulación de la movilización social y política en contra de la vía. En el debate que se suscitó en la opinión pública, AUDASA fue siempre a remolque de las iniciativas de los colectivos sociales y organizaciones políticas que se opusieron a la construcción de la autopista. Su reacción fue muy tardía y no resulta fácil valorar hasta qué punto los argumentos esgrimidos por la empresa tuvieron eco a nivel social.

En octubre de 1977, medio año después de que el gobierno optara por la paralización parcial de las obras, la empresa hacía público un informe en el que explicaba sus razones para continuar la construcción de la vía y rebatía los argumentos de sus detractores. AUDASA insistía en que la inversión en nuevas infraestructuras de comunicación era una prioridad estatal, así como en la obligación de la empresa de dedicar el $50 \%$ de sus beneficios - una vez que la obra estuviera amortizada - a cuestiones de interés público, como la mejora de la red viaria convencional o de las infraestructuras turísticas del país.

La empresa negaba que la mayor parte de las tierras afectadas por el trazado fuesen de cultivo (aunque sí eran de monte), estimando que la construcción afectaría sólo a 750 Has., el 0'04\% de la superficie total dedicada en Galicia a pastos y otros cultivos, frente al $40 \%$ esgrimido por los colectivos que se oponían a la vía. Consideraba que el sistema de comunicaciones terrestres alternativo propuesto por el CIES y apoyado por la Coordinadora Nacional de Afectados por la Autopista del Atlántico, supondría la expropiación de 600 Has. más que la construcción de la autopista e implicaría un coste superior en unos 14.000 millones de pesetas.

Para los objetivos de este trabajo tiene especial interés el análisis del informe técnico que la concesionaria elaboró y publicó en septiembre de 1976: La Autopista del Atlántico y sus efectos en el desarrollo de Galicia, que sirvió como base argumental del discurso que la empresa sostuvo en el marco del conflicto y que expresaba con claridad los principios del

\footnotetext{
${ }^{59}$ En mayo de 1978 AUDASA presentaba a la opinión pública las conclusiones de un sondeo de opinión encargado a la empresa Metra6/Marketing, según el cual el 75\% de los gallegos consultados eran partidarios de la continuación de las obras de construcción de la autopista, mientras que un 14\% apoyaba su paralización. Un 88\% de la muestra juzgaba la obra necesaria o conveniente, frente a un $8 \%$ que lă veía innecesaria. Un 75\% de los interpelados la entendía como beneficiosa para Galicia, frente a un $17 \%$ que pensaba que no suponía ventaja alguna para el país. Finalmente, entre las personas directamente afectadas que habían sido consultadas, el 51\% defendía la continuación de las obras, porcentaje que ascendía a un $69 \%$ en el caso de que los problemas derivados de las expropiaciones de tierras se solucionaran de manera satisfactoria. El País. Madrid, 18 de mayo de 1978.

${ }^{60}$ El País. Madrid, 22 y 23 de junio de 1978. La empresa estimaba en 12.000 millones de pesetas de 1978 el coste para el Estado de una eventual reversión de la concesión. El País. Madrid, 8 de octubre de 1977.

61 "Se han tenido en cuenta en este análisis todos los antecedentes históricos, sociales y económicos de Galicia como zona deprimida y la experiencia que situaciones similares, en otras naciones, ha supuesto la construcción de autopistas que servían de palanca para la superación de muchòs de sus inconvenientes de desarrollo y expansión". IDASA (Ingeniería del Atlántico S.A.). La Autopista del Atlántico y sus efectos en el desarrollo de Galicia, (A Coruña, 1976), 3.
} 
paradigma modernizador que subyacía al proyecto. El hecho de que el informe sea anterior a la aparición de las primeras manifestaciones de descontento provocadas por la construcción de la autopista, le aporta si cabe mayor valor analítico, pues sus autores se mostraban absolutamente convencidos de la trascendencia de la infraestructura para el progreso económico de Galicia, y confiados en que su acogida social sería positiva. Por eso, la naturaleza del documento es simplemente explicativa ante la opinión pública gallega.

Se trata de un texto elaborado por un equipo de ingenieros de caminos y economistas, que se caracteriza por su lenguaje "científico" y por la utilización de un tono neutro y moderadamente optimista, que sirve a un tiempo para calcular los potenciales beneficios económicos de la autopista y minimizar sus impactos sociales. ${ }^{62}$ En su tesis central se establece una relación directa entre la construcción y puesta en funcionamiento de una autopista y los efectos multiplicadores sobre el desarrollo económico del territorio que atraviesa, en el caso concreto de la Autopista del Atlántico, sobre la economía gallega, tal y como muestran los fragmentos que se reproducen a continuación:

La circulación del tráfico crea en las zonas de paso una demanda potencial y genera actividades nuevas jugando un papel impulsor. La rapidez del tránsito, permitida por la nueva infraestructura, produce cambios entre productores y expedición de bienes hacia mercados de consumo a costes más bajos, y actúa sobre el modelo espacial agrícola de las regiones atravesadas. ${ }^{63}$

La Autopista del Atlántico permitirá que distancias regionales se conviertan en teóricas distancias comarcales. Permitirá a su vez que se pueda reestructurar el territorio y abordar una coherente planificación urbanística, que se produzcan economías de escala en la producción y en el desarrollo de los sectores, que aumente el suelo a industrializar y, en general, se alcancen esos objetivos económicos que Galicia desea. Pero siempre, claro está, que esos beneficios potenciales que la Autopista del Atlántico aportará, sean convenientemente empleados dentro de una lógica política de utilización de los recursos disponibles. ${ }^{64}$

El discurso de los autores del informe técnico de AUDASA compartía la lógica del modelo de modernización económica por "difusión geográfica" puesto en marcha por las elites políticas franquistas durante el desarrollismo. ${ }^{65}$ No por casualidad, los técnicos de la empresa concebían la autopista como la pieza decisiva del entramado industrializador que el estado franquista había ido construyendo en la región desde los años sesenta. ${ }^{66}$

El informe enumeraba una serie de beneficios complementarios derivados de la construcción de la Autopista del Atlántico. Sin vocación de exhaustividad podemos citar

\footnotetext{
${ }^{62}$ Abundan las referencias a la literatura científica especializada en el tema, así como la presentación de modelos econométricos para evaluar el futuro impacto económico de la infraestructura. El Colegio Oficial de Ingenieros de Caminos, Canales y Puertos de Galicia fue el colectivo profesional que más abiertamente apoyó la construcción de la Autopista del Atlántico, como atestigua el Informe sobre la Problemática de la Autopista del Atlántico que elaboró y divulgó en el otoño de 1977.

${ }^{63}$ IDASA. La Autopista del, 48-49.

64 IDASA. La Autopista del, 76.

${ }^{65}$ Los principales hitos de este modelo en Galicia fueron los Polos de Desarrollo de Vigo y A Coruña (1964), la creación en 1972 de la Sociedad para el Desarrollo Industrial de Galicia (SODIGA) y del Gran Área de Expansión Industrial de Galicia (1973) y, más adelante, la mejora de los accesos a Galicia desde la meseta. Marta Fernández, Jesús Mirás, "Política regional y localización industrial en Galicia" en IX Congreso de la Asociación Española de Historia Económica (Murcia: Universidad de Murcia, 2009).

${ }^{66}$ Incluso se atrevían a cuantificar los efectos positivos de la autopista sobre la economía española: "La aplicación de este multiplicador a la inversión de la autopista ofrece ūn efecto de casi 80.000 millones de pesetas sobre la renta nacional. Es indudable que la mayor parte de este efecto incidirá directamente sobre la renta de Galicia." IDASA. La Autopista del, 97.
} 
entre ellos la creación de empleo durante la fase de construcción de la autopista ${ }^{67}$, el incremento de la recaudación de la Hacienda pública como consecuencia de la actividad de la propia vía, el ahorro de tiempo en los desplazamientos, la descongestión de las carreteras convencionales de la red estatal, los incrementos en la seguridad y el confort de los usuarios, el descenso de la siniestrabilidad, los ahorros en mecánica y desgaste de los vehículos, etc.

Por el contrario, los costes no monetarios, es decir, los costes sociales derivados de la construcción y puesta en funcionamiento de la autopista, pasaban casi eufemísticamente desapercibidos en el informe técnico elaborado por los ingenieros de la consultora IDASA:

[...] costes sociales o secundarios, que son los inconvenientes que la colectividad debe soportar para que sea posible la realización de la autopista. Estos costes sociales son, por ejemplo, la renuncia forzada a una parte de la propiedad particular por el efecto de expropiación, la posible afección del paisaje y otros costes relativos [...] como ruido, polución, accidentes, etc. ${ }^{68}$

\section{Conclusiones}

Los discursos que la Administración (forestal) del Estado y las grandes empresas elaboraron en el marco de la conflictividad ambiental durante el franquismo y los primeros años de la transición a la democracia tenían muchos elementos en común. Aún a pesar de la apreciable distancia cronológica que separa los conflictos que aquí hemos analizado.

En primer lugar, ambos tipos de discurso eran del todo coherentes con la filosofía que informaba la política económica en cada periodo. El discurso de los ingenieros de montes al servicio del Patrimonio Forestal del Estado durante las décadas de 1940 y 1950, encajaba a la perfección con la voluntad autárquica de maximizar el aprovechamiento de los recursos naturales endógenos. En un contexto de escasez, aislamiento internacional y zozobra en cuanto a la supervivencia política del franquismo, la vertiente forestal de la autarquía se verbalizó en un discurso patriótico que imponía el "bien superior de la nación" sobre cualquier otro tipo de consideración.

En los años setenta - en el zénit de la influencia política e intelectual de los paradigmas del atraso y la modernización (desarrollo) - para el discurso empresarial, la modernización económica (entendida como industrialización) representaba la panacea para el progreso del país a todos los niveles. De hecho, las elites económicas y políticas españolas de la década de 1970 compartían un mismo discurso, lo que no sorprende si tenemos en cuenta la gran permeabilidad existente entre ambos grupos durante la fase desarrollista de la dictadura. En el discurso modernizador de los setenta hay también elementos autárquicos, pero no se trata de un pensamiento autárquico de inspiración fascista, sino de una mirada forzosa hacia los recursos propios causada por la interdependencia de las economías occidentales de posguerra, sacudidas por la crisis del petróleo. En todo caso, ambos escenarios económicos fueron propicios para los intereses de las grandes empresas (públicas o privadas) españolas.

\footnotetext{
${ }^{67}$ El informe enfatizaba en la importancia de la creación de empleo en el contexto de la depresión económica de la segunda mitad de la década de 1970: "Un último efecto derivado de la construcción de la Autopista es el empleo de la mano de obra necesaria para su realización. Se estima en unos 4 millones de jornadas laborales, lo que viene a representar más de 5.000 millones de pesetas (...) este valor debe tenerse presente por su especial significado social en unas circunstancias como las actuales." IDASA. La Autöpista del, 99.

${ }^{68}$ IDASA. La Autopista del, 58.
} 
Tanto la Administración como las grandes corporaciones construyeron sus discursos ya fuera para su consumo burocrático o estuvieran destinados a la opinión pública empleando de forma recurrente argumentos científico - técnicos. ¿Quién podría saber mejor que los ingenieros forestales cuáles eran las características físicas del monte gallego y cuál su forma de explotación más racional y eficiente? ¿Quién como FENOSA para explicar a la sociedad gallega la importancia de la producción eléctrica para la industrialización del país y la elevación del nivel de vida de la población? ¿Había alguien más capacitado que los ingenieros de caminos y economistas de AUDASA para ilustrar la benéfica relación entre grandes infraestructuras de comunicación y estímulos al desarrollo económico regional? La dimensión técnica de estos discursos reforzaba el desprecio de la racionalidad en la que se sustentaban las reivindicaciones de las comunidades rurales en el curso de los conflictos ambientales. Para los ingenieros del PFE los labradores y su modo de vida eran atrasados, ignorantes y rutinarios, lo que les impedía ser conscientes de que la repoblación forestal era en realidad la opción económicamente más beneficiosa para sí mismos. En los conflictos de Encrobas y la Autopista del Atlántico las empresas, aún reconociendo los perjuicios causados por las expropiaciones, se mostraron absolutamente insensibles al impacto que una enorme modificación del territorio estaba causando en las actividades cotidianas, en la identidad social y en el mundo simbólico de las comunidades afectadas. Su discurso asumía implícitamente que alguien (una minoría) tenía que hacerse cargo, en aras del beneficio colectivo, de los inevitables costes del progreso.

Un último elemento común aproxima ambos discursos y periodos históricos: la cuestión del empleo, un argumento socialmente muy sensible, ya fuera en los tiempos de escasez material de la posguerra o de extensión del desempleo que caracterizó a la crisis de la economía española de la segunda mitad de los setenta.

Sin embargo, existe una gran diferencia entre el discurso de los técnicos de la Administración forestal y el de empresas como FENOSA - LIMEISA o AUDASA. No se encuentra tanto en su naturaleza o contenidos como en el contexto social y político en el que estos fueron emitidos. En los años cuarenta y cincuenta, los ingenieros forestales no tenían ninguna necesidad de justificar o legitimar sus actuaciones ante la sociedad. La política de repoblación forestal, más allá de las numerosas resistencias campesinas que encontró sobre el terreno, simplemente, se aplicaba. El poder del aparato del Estado (y de sus instrumentos de coacción) era tal que cualquier actor que se opusiera desde fuera de la estructura institucional a las políticas del régimen muy difícilmente habría podido generar algo parecido a un debate público. De ahí que el discurso de la Administración forestal tenga que ser interpretado dentro de los límites de los procedimientos administrativos (como sucede con los consorcios) o, a lo sumo, judiciales.

Por los motivos contextuales que ya hemos explicado, FENOSA, AUDASA y otras grandes empresas tuvieron que elaborar, en el marco de diferentes conflictos ambientales, discursos y estrategias de comunicación destinados a ser confrontados por otros actores e intereses en el ámbito de una opinión pública en proceso de acelerada articulación. Las grandes corporaciones tardaron algún tiempo en adaptarse a un escenario hasta entonces desconocido. Pero en cuanto lo hicieron, utilizaron con fluidez todos los recursos a su alcance. Tuvieron un acceso privilegiado al conglomerado de medios de comunicación de titularidad estatal (aún en proceso de democratización) ${ }^{69}$, sin por ello renunciar a emplear los medios de capital privado para el envío de notas de prensa a través de las que rebatían los argumentos de sus detractores o intentaban crear estados de opinión. Pero sobre todo, para

\footnotetext{
${ }^{69}$ El conglomerado de "Medios de Comunicación Sòcial del Estado", o "Prensa del Movimiento" no desapareció por ley
} hasta 1981. 
comprar amplios espacios publicitarios. El recurso a una intensa publicidad empresarial fue especialmente importante coincidiendo con los picos de mayor intensidad de los conflictos.

Por tanto, la existencia de una opinión pública "moderna" (casi democrática), en la que se contrastaban los discursos y contradiscursos de los actores que participaban en los conflictos, fue la principal novedad del periodo. Mucho más difícil (y fuera del alcance de este trabajo) es medir el impacto real que estos discursos tuvieron en la conformación de la opinión de. la sociedad gallega del momento. 